\title{
Pendampingan Pengisian Kuisioner Online Berbasis QTAFI bagi Alumni STKIP Andi Matappa
}

\author{
Muhammad Taqwa ${ }^{*}$, Firdha Razak ${ }^{1}$
}

1STKIP Andi Matappa, Jl. Andi Mauraga No. 70 Pangkajene, Kab. Pangkep, Indonesia, 90611

*Email koresponden: muh.taqwa@stkip-andi-matappa.ac.id

\author{
ARTICLE INFO \\ Article history \\ Received: 25 Agt 2020 \\ Accepted: 17 Mar 2021 \\ Published: 24 Apr 2021
}

\section{Kata kunci:}

Alumni

QTAFI

Tracer study

\section{Keyword:}

Graduate

QTAFI.

Tracer study

\begin{abstract}
A B S T R A K
Background: Cara memperoleh informasi ataupun umpan balik dari alumni, perguruan tinggi memerlukan sebuah metode, salah satunya adalah tracer study. Melalui tracer study, perguruan tinggi akan mengetahui outcome pendidikan dari alumni berupa transisi dari dunia pendidikan tinggi ke dunia kerja dan perbaikan serta pengembangan kualitas dari sistem pendidikan perguruan tinggi yang mereka peroleh selama perkuliahan. STKIP Andi Matappa merupakan perguruan tinggi swasta yang rutin melaksanakan tracer study setiap tahun. Akan tetapi, banyak alumni STKIP Andi Matappa yang masih belum paham dan sadar akan pentingnya tracer study. Hal ini diperparah dengan banyak alumni STKIP Andi Matappa yang berdomisili di daerah terpencil. Metode: Pendampingan pengisian kuisioner online QTAFI untuk tracer study dengan metode pelatihan simulasi pada alumni STKIP Andi Matappa Tahun 2019. Tujuan kegiatan pendampingan yaitu meningkatnya pengetahuan dan pemahaman alumni mengenai pengisian kuisioner online QTAFI. Adapun langkah-langkah kegiatan pendampingan pengisian kuisioner tracer study berbasis QTAFI bagi alumni STKIP Andi Matappa yaitu (1) Tahap pengenalan, (2) Penjelasan data isian dalam kuisioner tracer study berbasis QTAFI, (3) Bimbingan teknis pengisian kuisioner tracer study berbasis QTAFI. Hasil: Meningkatnya pengetahuan dan pemahaman alumni STKIP Andi Matappa mengenai pengisian kuisioner online QTAFI untuk tracer study. Kesimpulan: Sosialisasi dan pendampingan yang lebih menyeluruh dapat dijadikan saran agar pelaksanaan Tracer study pada periode berikutnya menjadi lebih efektif.
\end{abstract}

\section{A B S T R A C T}

Background: In obtaining information or feedback from alumni, universities require methods to be used in this regard, one of which is tracer study. Through tracer study, universities will know the educational outcomes of alumni in the form of transition from the world of higher education to the world of work and improvement and quality development of the college education system that they obtained during the lecture. STKIP Andi Matappa is a private university that routinely conducts tracer studies every year. However, many alumni of STKIP Andi Matappa still do not understand and are aware of the importance of tracer study. This is exacerbated by the many alumni of STKIP Andi Matappa who live in remote areas. Methods: Assistance in filling out QTAFI online questionnaires for tracer studies using simulation training methods for alumni of STKIP Andi Matappa in 2019. The purpose of the mentoring activity is increased knowledge and understanding of alumni regarding the filling of QTAFI online questionnaires. The steps of QTAFI-based tracer study questionnaire filling assistance activities for STKIP Andi Matappa alumni are (1) Introduction stage, (2) Explanation of fill data in QTAFI-based tracer study questionnaire, (3) Technical guidance on filling out QTAFI-based tracer study questionnaires. Result: The dedication showed the increasing knowledge and understanding of Graduate of STKIP Andi Matappa regarding the filling of QTAFI online questionnaires for tracer study. Conclusion: More comprehensive socialization and assistance can be used as a suggestion so that the implementation of the Tracer study in the next period will be 
more effective.

(ㅇ 2021 by authors. Lisensi Jurnal Solma, UHAMKA, Jakarta. Artikel ini bersifat open access yang didistribusikan di bawah syarat dan ketentuan Creative Commons Attribution ( $\underline{\mathrm{CC}-\mathrm{BY}})$ license.

\section{PENDAHULUAN}

Upaya akademik yang berkaitan dengan pendidikan tinggi dan dunia kerja bisa dijumpai di negara maju seperti di Amerika Utara, Eropa Barat, Jepang maupun Singapura, akan tetapi di Indonesia upaya tersebut belum begitu banyak mendapatkan perhatian (Kemendikbud, 2012). Meskipun banyak perguruan tinggi di Indonesia telah berupaya melakukan penelusuran terhadap alumninya (tracer study), namun hasil yang diperoleh belum sesuai harapan. Bagi perguruan tinggi, keberhasilan proses pendidikan yang telah dilakukan dapat dilihat dari hasil dari tracer study.

Tracer study adalah studi mengenai lulusan lembaga penyelenggara pendidikan tinggi (Schomburg, 2003; Wahyuddin, 2016). Menurut Fajaryati et al., (2015) Tracer study merupakan studi yang tujuan utamanya untuk memperoleh informasi mengenai lulusan yang sudah bekerja dan belum bekerja. Sedangkan menurut ILO, (2011); Suryani \& Khairuin, (2015) bahwa tracer study merupakan suatu metode untuk menelusuri informasi suatu sampel yang telah diberikan intervensi tertentu yang pada waktunya akan mendatangkan dampak sesuai yang diinginkan. Istilah lain Tracer study menurut Fahmi, (2017) juga sering digunakan adalah "Graduate Surveys", "Responden Researches", dan "Follow-up Study". Informasi mengenai keterkaitan antara pendidikan tinggi dan dunia kerja professional, relevansi pendidikan tinggi, informasi bagi pemangku kepentingan (stakeholder), kelengkapan persyaratan bagi akreditasi pendidikan tinggi serta sebagai evaluasi hasil pendidikan tinggi yang kemudian digunakan sebagai penyempurnaan dan penjaminan kualitas lembaga pendidikan tinggi bersangkutan merupakan manfaat yang bisa diperoleh dari tracer study (Kemendikbud, 2012).

Menurut Kemendikbud (2012), keberadaan tracer study di Indonesia saat ini bisa dikatakan masih tahapan awal. Analisis yang dilakukan oleh Syafiq \& Fikawati (2008) menunjukkan bahwa sampai saat ini informasi dan publikasi mengenai tracer study di perguruan tinggi di Indonesia masih sangat sedikit dibandingkan di negara maju khususnya di negara Eropa yang telah menghasilkan penelitian besar melalui jejaring tracer studynya. Hasil analisis tersebut juga menemukan bahwa tracer study di Indonesia sangat bervariasi dari segi kejelasan tujuan, desain, dan metodologinya. Jika dibandingkan dengan perkembangan tracer study di negara maju, situasi di Indonesia tertinggal cukup jauh.

STKIP Andi Matappa merupakan salah satu perguruan tinggi swasta yang rutin melaksanakan tracer study setiap tahun bagi alumninya. Akan tetapi, respon rate pada Tracer study STKIP Andi Matappa pada tahun 2017 hanya mencapai 39\% (Muchsin, S \& Hasbahuddin, 2018). Mengingat pentingnya data tracer study bagi STKIP Andi Matappa, maka diperlukan inovasi dan perbaikan untuk mempermudah proses pengambilan data yang akan rutin setiap tahun 
dilakukan. Inovasi dan perbaikan dalam proses tracer study setiap tahun disesuaikan dengan perkembangan teknologi. Tidak dapat dipungkiri bahwa kemajuan teknologi saaat ini tidak dapat dipisahkan dari kehidupan masyarakat (Wahyudi \& Sukmasari, 2014). Teknologi memberikan banyak kemudahan dan dapat dipandang sebagai cara baru dalam melakukan aktivitas manusia (Ngafifi, 2014). Dalam hal ini program QTAFI ditujukan untuk mempermudah proses pengambilan data tracer study. QTAFI ini pertama kali diluncurkan untuk tahun 2003 oleh Martin Guist. QTAFI mempunyai kelebihan atau keunggulan aplikasi ini dan penerapannya yang sangat user frendly sangat membantu bagi manajemen administrasi dan pengolahan data bagi institusi yang akan melakukan survei, misalnya survei sejenis tracer study (Ratnaningsih, D, 2010).

Inovasi ini tentunya tidak terlepas dari masalah atau kendala. Faktor sosial, ekonomi dan geografis merupakan faktor yang mempengaruhi alumni dalam literasi teknologi informasi dan komunikasi (Syarifuddin, 2014). Fakta menunjukkan bahwa banyak alumni perguruan Tinggi yang masih belum memahami dan menyadari pentingnya tracer study. Hal yang sama juga dialami alumni STKIP Andi Matappa yang mayoritas alumninya berdomisili di daerah terpencil. Rendahnya partisipasi alumni dalam pengisian tracer study serta kurangnya sosialiasi mengenai pentingnya dan bagaimana prosedur pengisian tracer study dengan QTAFI juga menjadi alasan banyaknya alumni yang belum berpartipasi dalam pengisian tracer study. Diketahui adapun respon rate berdasarkan prodi yaitu $41 \%$ jurusan pendidikan matematika dan 59 \% jurusan Bimbingan dan Konseling yang sudah berpartisipasi pada pengisian tracer study 2017 (Muchsin, S \& Hasbahuddin, 2018). Fakta di lapangan tersebutlah yang melandasi dilakukan kegiatan pendampingan kepada alumni STKIP Andi Matappa tentang apa dan bagaimana pengisian kuisioner tracer study berbasis QTAFI. Tujuan dengan diadakan pendampingan kepada alumni ini adalah agar lebih banyak alumni dapat ikut berpartisipasi dan lebih mudah dalam pengisian data tracer study dengan QTAFI.

\section{MASALAH}

Mitra pengabdian masyarakat yang penulis lakukan ini adalah STKIP Andi Matappa. Walaupun memiliki jumlah alumni yang sangat banyak, akan tetapi proses tracer study belum berjalan secara kontinu setiap tahun. Bahkan respon rate pada Tracer study STKIP Andi Matappa pada tahun 2017 hanya mencapai 39\%. Sedangkan respon rate Tracer study STKIP Andi Matappa pada tahun yang sama berdasarkan prodi yaitu 41\% jurusan pendidikan matematika dan $59 \%$ jurusan Bimbingan dan Konseling. Padahal dengan Tracer study dapat menyediakan informasi berharga mengenai hubungan antara pendidikan tinggi dan dunia kerja profesional, menilai relevansi pendidikan tinggi, informasi bagi pemangku kepentingan (stakeholder), dan kelengkapan persyaratan bagi akreditasi pendidikan tinggi. Saat ini tracer study sudah dijadikan salah satu syarat kelengkapan akreditasi di Indonesia oleh Badan Akreditasi Nasional Perguruan Tinggi.

Fakta menunjukkan bahwa banyak alumni STKIP Andi Matappa yang masih belum paham dan sadar akan pentingnya tracer study. Hal ini diperparah dengan banyak alumni STKIP Andi Matappa yang berdomisili di daerah terpencil. Sehingga kesadaran alumni terhadap pentingnya berpartisipasi dalam pengisian tracer study masih rendah. Dengan melihat banyaknya 
permasalahan yang dihadapi dalam proses tracer study oleh alumni STKIP Andi Matappa maka perlu penggunaan survey online yang mudah, user friendly, serta sudah terbukti penggunaanya dalam tracer study. Salah satu survei online yang disarankan yaitu QTAFI. Maka ditawarkan solusi dalam pengabdian masyarakat yang berjudul Pendampingan Pengisian Kuisioner Tracer study berbasis QTAFI bagi Alumni STKIP Andi Matappa.

\section{METODE PELAKSANAAN}

Berdasarkan prioritas permasalahan Mitra yaitu STKIP Andi Matappa maka sesuai kepakaran yang dimiliki dan kesepakatan dengan Mitra untuk jangka waktu pelaksanaan kegiatan yang hanya 1 (satu) hari dan nantinya dibuat berkelanjutan disetiap tahun sebelum wisuda. Pendekatan untuk menemukan solusi akan menyelesaikan permasalahan kurangnya alumni yang mengisi kuisioner tracer study. Maka pendekatan pendampingan yang dilakukan adalah dengan metode pelatihan simulasi. Simulasi adalah satu metode pelatihan yang memperagakan sesuatu dalam bentuk tiruan (imakan) yang mirip dengan keadaan yang sesungguhnya; simulasi: penggambaran suatu sistem atau proses dengan peragaan memakai model statistik atau pemeran (Depdiknas, 2005). Proses pembelajaran yang menggunakan metode simulasi cenderung objeknya bukan benda atau kegiatan yang sebenarnya, melainkan kegiatan mengajar yang bersifat purapura (Anitah, 2007). Lokasi Pelaksanaan pendampingan yaitu STKIP Andi Matappa pada Tanggal 31 Juli Tahun 2019 pukul 08.00 - 11. 30 WITA. Kelompok sasaran yaitu alumni STKIP Andi Matappa Tahun 2019. Adapun Langkah-langkah kegiatan pendampingan pengisian kuisioner tracer study berbasis QTAFI bagi alumni STKIP Andi Matappa menggunakan metode simulasi yaitu (1) tahap pengenalan, (2) penjelasan data isian dalam kuisioner tracer study berbasis QTAFI, (3) bimbingan teknis pengisian kuisioner tracer study berbasis QTAFI

\section{HASIL DAN PEMBAHASAN}

Hasil kegiatan pendampingan pengisian kuisioner tracer study berbasis QTAFI bagi alumni STKIP Andi Matappa ini sebagai berikut:

a. Alumni STKIP Andi Matappa sangat antusias dengan adanya pendampingan ini, dan sangat banyak alumni yang mengajukan pertanyaan seputar pertanyaan di kuisioner tracer study serta kegunaan pengisian tracer study. Hal ini ditunjukkan dengan 67 dari 70 alumni yang terdapat di alumni tahun 2019 sudah berpartisipsi dalam pengisian kuisioner tracer study berbasis QTAFI secara benar pada setiap item kuisioner tracer study.

Gambar 1. Bimbingan teknis pengisian kuisioner tracer study berbasis QTAFI 
b. Alumni STKIP Andi Matappa mengapresiasi kegiatan ini dan berharap ada kegiatan rutin terutama bagi alumni yang belum diwisuda.

c. Tahap Penjelasan Isian Data dan Bimbingan Teknis

1. Tampilan awal dan tampilan utama Survei Online yang dapat diakses melalui link berikut: http://tracer2.stkip-andi-matappa.ac.id/qtafi/projects/tracer2019/

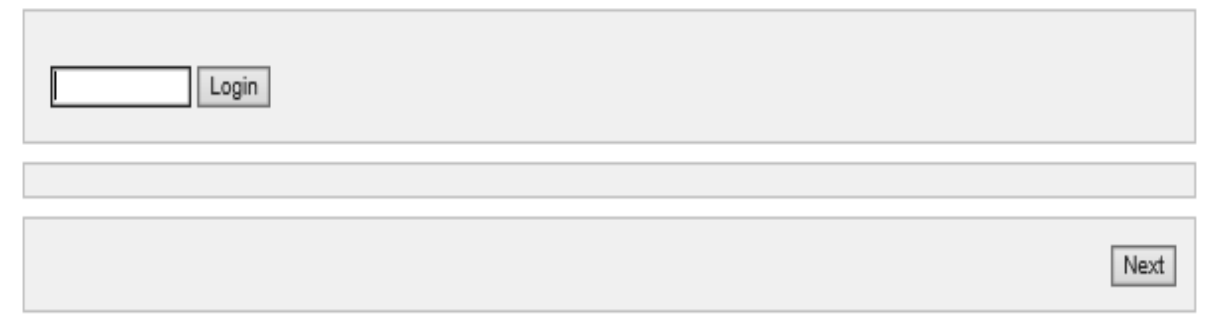

Gambar 2. Halaman Login

2. Pin registrasi akan diberikan dengan menghubungi pengelola tracer study STKIP Andi Matappa atau email: cdc@stkip-andi-matappa.ac.id atau cdc.stkipandimatappa@gmail.com. Setelah memperoleh pin, maka klik tombol login

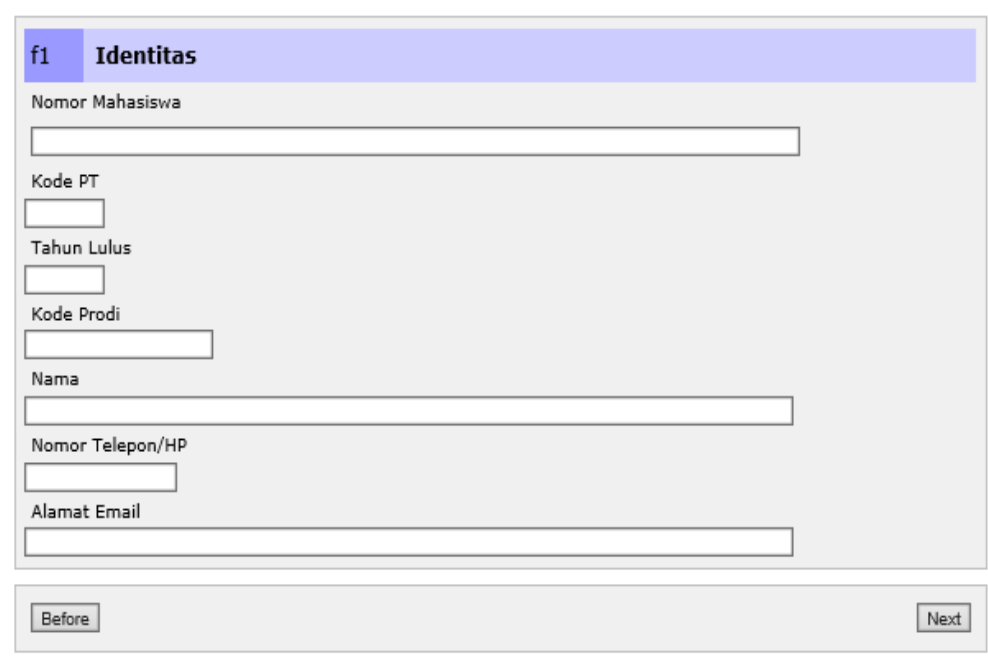

Gambar 3. Halaman Identitas

3. Pada bagian identitas disajikan arahan antara lain: (1) Nomor Mahasiswa diisi menggunakan Nomor induk Mahasiswa, (2) Kode Perguruan Tinggi diisi dengan kode PT STKIP Andi Matappa yaitu “093097”, (3) Tahun Lulus diisi lengkap tahun lulus(wisuda), (4) Kode Prodi diisi untuk jurusan Pendidikan Matematika kodenya "84202 " sedangkan untuk jurusan Bimbingan dan Konseling Kodenya "86201 ", (5) Nama diisi sesuai dengan nama di ijazah, (6) Nomor HP diisi nomor handpone yang aktif, dan (7) alamat email aktif, apabila selesai, silakan tekan tombol "Next". 

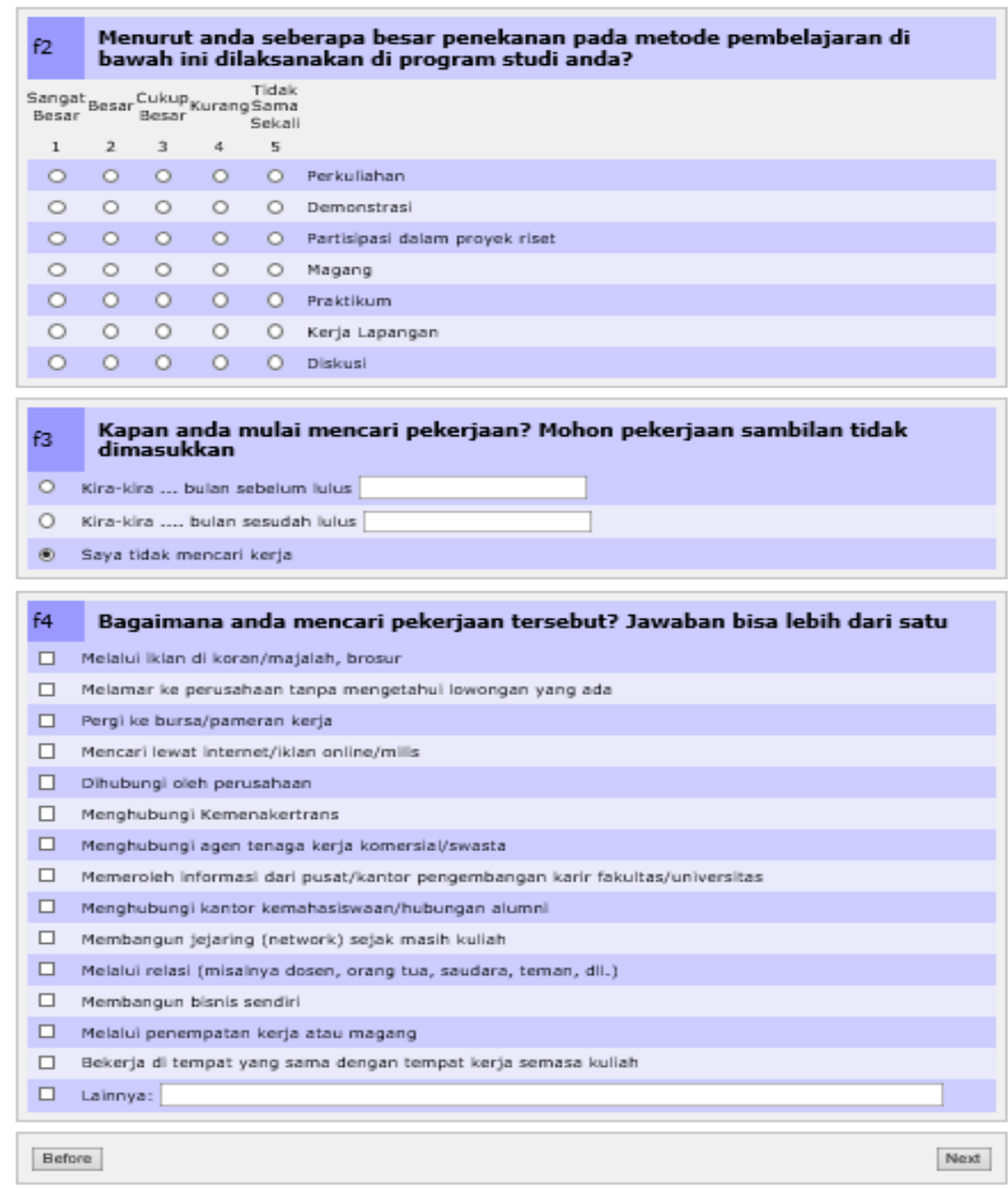

Gambar 4. Kuisioner Tracer Study DIKTI f2 - f4 menggunakan software QTAFI

4. Pada bagian kedua disajikan arahan antara lain: (1) Metode Pembelajaran selama kuliah mulai perkuliahan, demonstrasi, partisipasi dalam proyek riset, magang, praktikum, kerja lapangan hingga diskusi dengan rentang penilaian sangat besar sampai tidak sama sekali. (2) Waktu mencari Pekerjaan Utama diisi dengan satuan bulan misalkan 3 berarti tiga bulan, (3) Cara Memperoleh Pekerjaan Utama opsi jawaban memungkinkan lebih dari satu jawaban, apabila selesai, silakan tekan tombol "Next". 


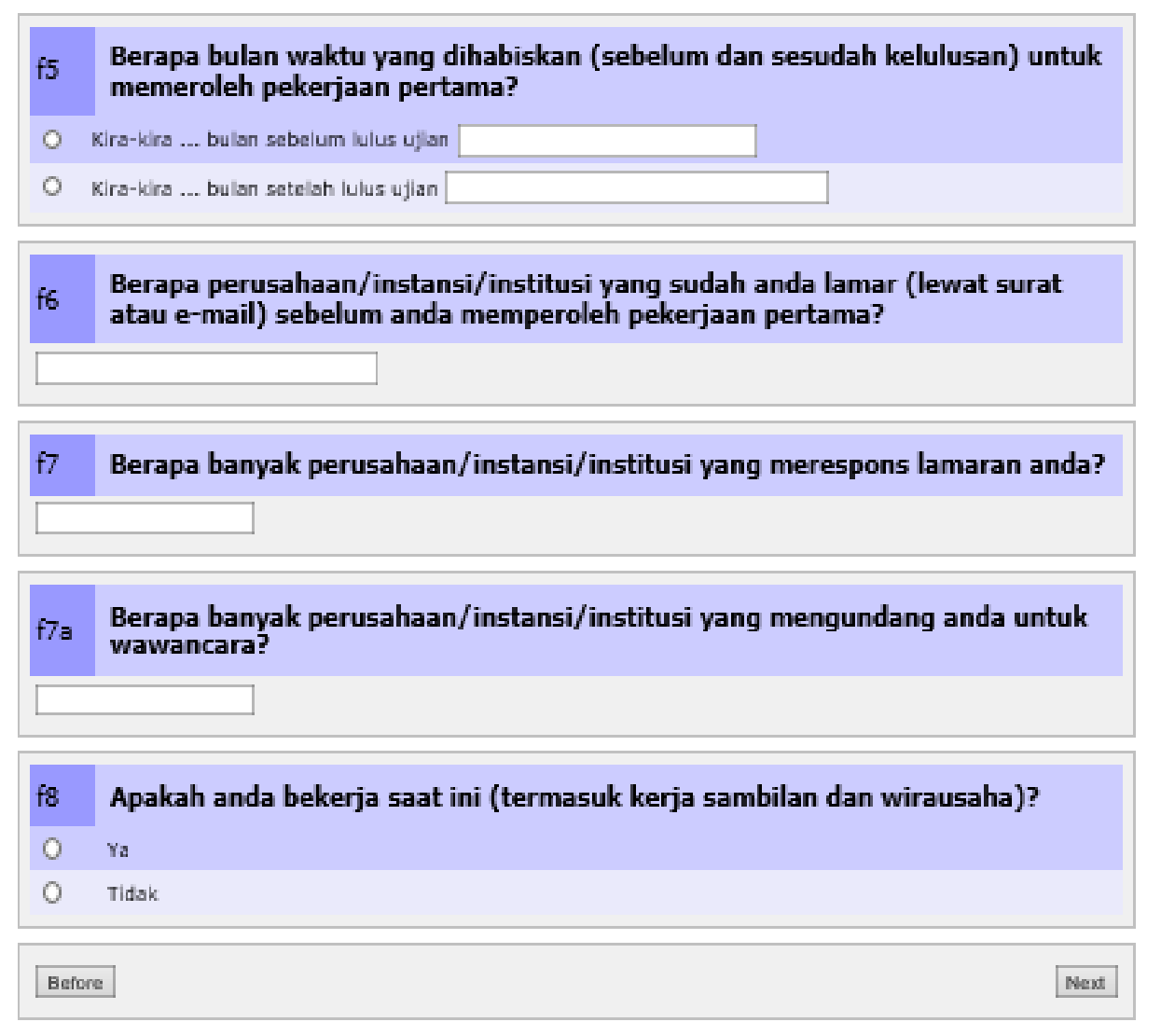

Gambar 5. Kuisioner Tracer Study DIKTI f5-f8 menggunakan software QTAFI

5. Pada bagian ketiga disajikan arahan antara lain: (1) Waktu yang diperlukan untuk memperoleh pekerjaan berdasarakan tahun lulus diisi dengan satuan bulan, (2) Banyak lamaran yang diajukan sebelum bekerja diisi dengan angka saja misalkan 3 lamaran berarti cukup diisi dengan angka 3, (3) Banyak perusahaan yang merespon lamaran diisi dengan angka saja, (4) Banyak perusahaan yang mengundang wawancara diisi dengan angka saja, (5) Jenis Pekerjaan pilih salah satunya saja, apabila selesai, silakan tekan tombol "Next".

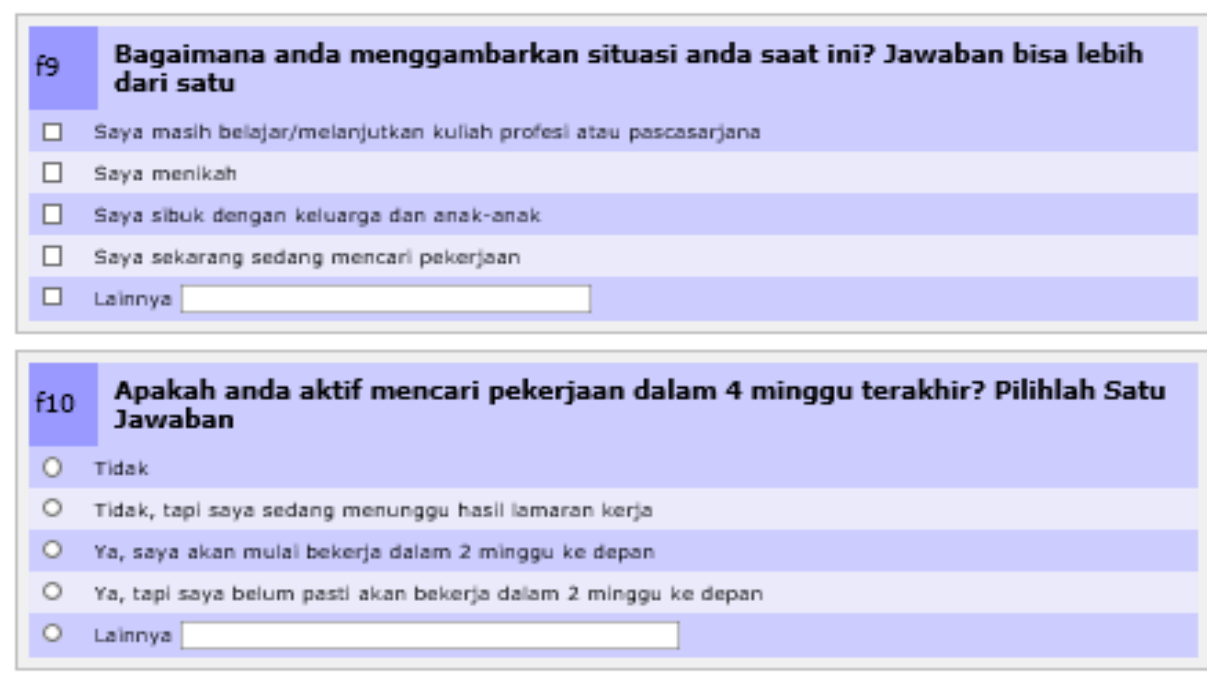




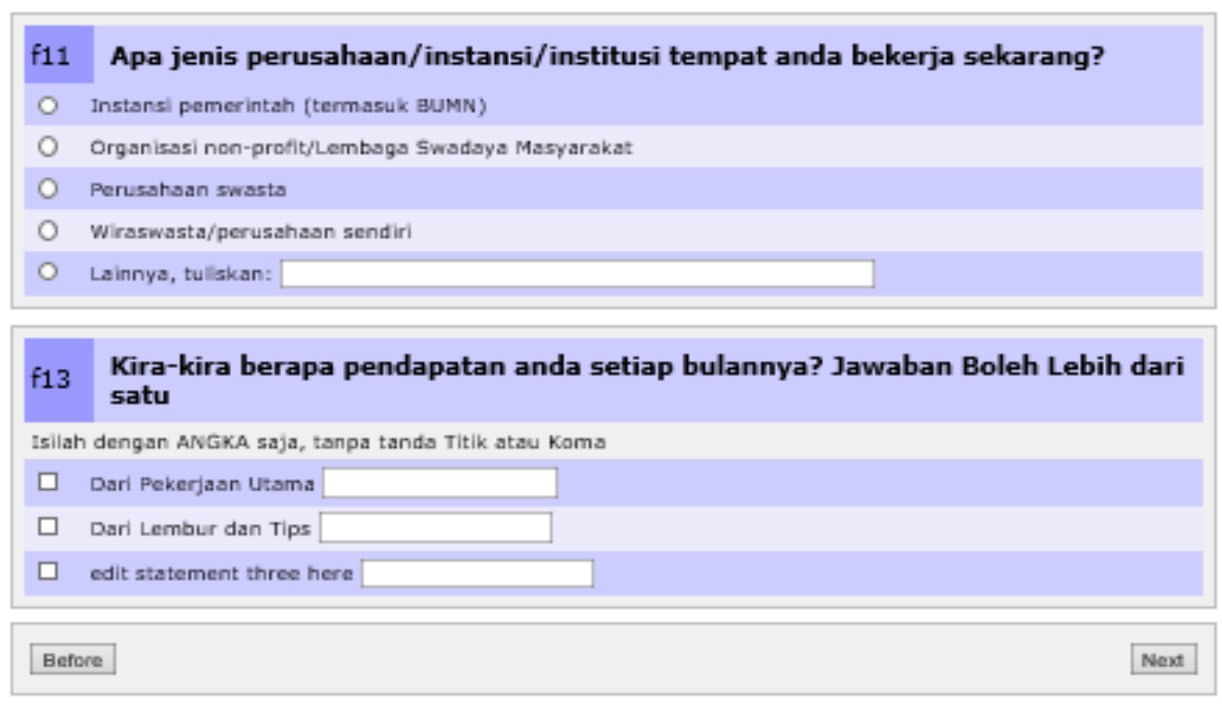

Gambar 6. Kuisioner Tracer Study DIKTI 99 - f13 menggunakan software QTAFI

6. Pada bagian keempat disajikan arahan antara lain: (1) Keadaan Alumni opsi jawaban memungkinkan lebih dari satu jawaban, (2) Keaktifan mencari kerja sebulan terakhir opsi jawaban hanya memilih satu jawaban atau menulis, (3) Jenis Instansi tempat bekerja opsi jawaban hanya memilih satu jawaban atau menulis, (4) Penghasilan opsi jawaban memungkinkan lebih dari satu jawaban. Besarnya penghasilan ditulis tanpa menggunakan satuan rupiah cukup angka saja, sebagai contoh 2400000, apabila selesai, silakan tekan tombol "Next".

7. Pada bagian kelima disajikan arahan antara lain: (1) Korelasi antara bidang studi dan pekerjaan hanya memilih satu jawaban, (2) Kesesuaian antara tingkat pendidikan dan pekerjaan hanya memilih satu jawaban, (3) Alasan Kesesuaian antara tingkat pendidikan dan pekerjaan opsi jawaban memungkinkan lebih dari satu jawaban atau menulis, apabila selesai, silakan tekan tombol "Next".

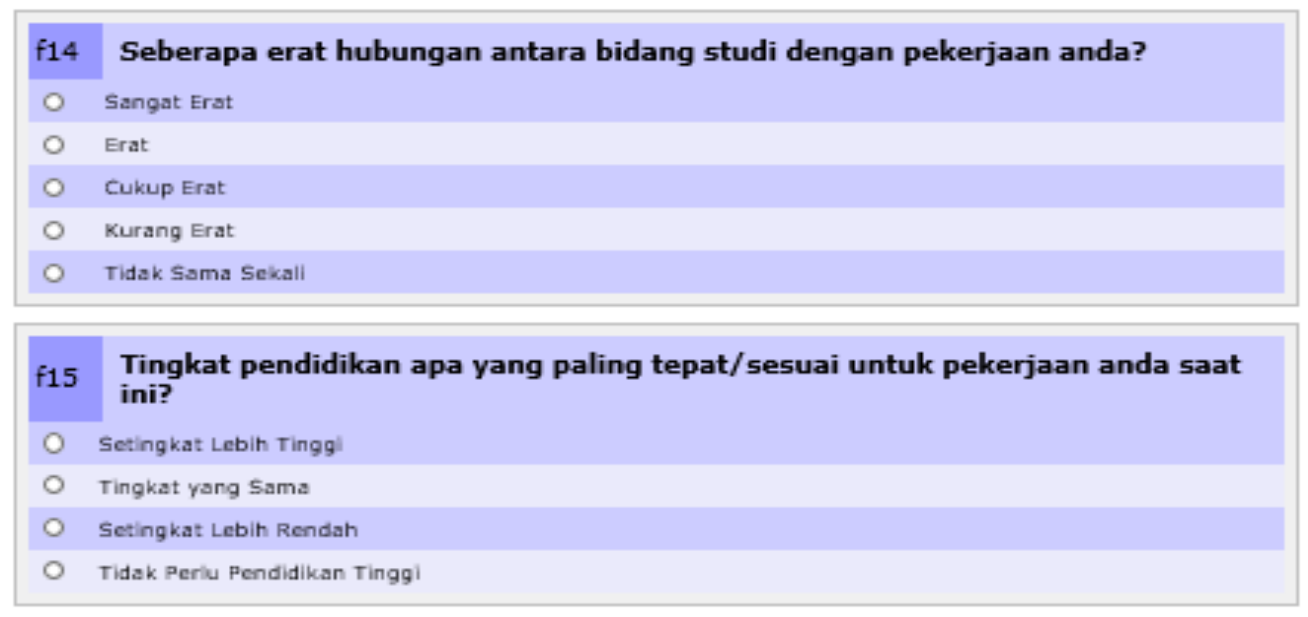




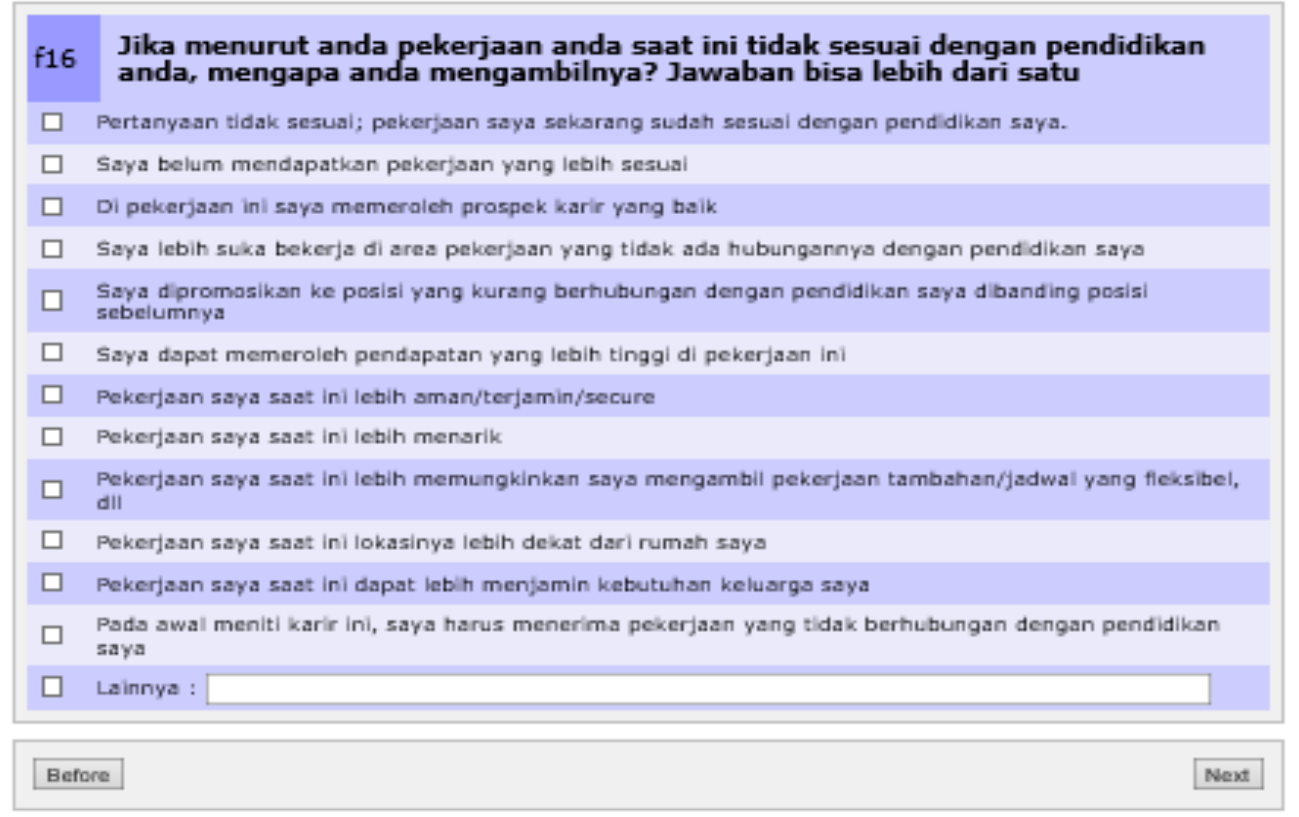

Gambar 7. Kuisioner Tracer Study DIKTI f14 -f16 menggunakan software QTAFI

8. Pada bagian keenam disajikan arahan antara lain: (1) Kompetensi alumni pada saat lulus mulai dari pengetahuan baik disiplin ilmunya maupun diluar disiplin ilmunya, pengetahuan umum, bahasa inggris, keterampilan internet, keterampilan komputer, berpikir kritis, keterampilan riset, kemampuan belajar, kemampuan berkomunikasi, bekerja di bawah tekanan, manajemen waktu, bekerja secara mandiri, bekerja dengan bekerjasama, kemampuan memecahkan masalah, negosiasi, kemampuan analisis, tolerasi, kemampuan adaptasi, loyalitas, integritas, bekerja dengan latar belakang berbeda, kepemimpinan, tanggung jawab, inisiatif, manajemen program, kemampuan presentasi, kemampuan menulis laporan, serta kemampuan belajar sepanjang hayat dengan rentang penilaian sangat rendah sampai sangat tinggi, apabila selesai, silakan tekan tombol "Next".

\begin{tabular}{|c|c|c|c|c|c|}
\hline \multirow{2}{*}{$\begin{array}{c}\mathrm{f} 17 \\
\text { Sangat } \\
\text { Rendah } \\
1\end{array}$} & \multicolumn{5}{|c|}{ Pada saat lulus, pada tingkat mana kompetensi di bavah ini anda kuasai? } \\
\hline & 2 & 3 & 4 & $\begin{array}{c}\text { Sangat } \\
\text { Tinggi } \\
5\end{array}$ & \\
\hline 0 & 0 & 0 & 0 & 0 & Pengetahuson di bidang atau disiplin ilmu anda \\
\hline 0 & 0 & 0 & 0 & 0 & Pengetahuson di luar bidang atau disiplin limu ands \\
\hline 0 & 0 & 0 & 0 & 0 & Pengetahuan umum \\
\hline 0 & 0 & 0 & 0 & 0 & Bahasa Inggris \\
\hline 0 & 0 & 0 & 0 & 0 & Ketrampilan internet \\
\hline 0 & 0 & 0 & 0 & 0 & Ketrampilan komputer \\
\hline 0 & 0 & 0 & 0 & 0 & Berpikir kritis \\
\hline 0 & 0 & 0 & 0 & 0 & Ketrampilan riset \\
\hline 0 & 0 & 0 & 0 & 0 & Kemampuan belajar \\
\hline 0 & 0 & 0 & 0 & 0 & Kemampuan berkomunikasl \\
\hline 0 & 0 & 0 & 0 & 0 & Bekerja di bawah tekanan \\
\hline 0 & 0 & 0 & 0 & 0 & Manajemen waktu \\
\hline 0 & 0 & 0 & 0 & 0 & Bekerja sccara mandiri \\
\hline 0 & 0 & 0 & 0 & 0 & Bekerja dalam tim/thekerjasama dengan arang lain \\
\hline
\end{tabular}




\begin{tabular}{|c|c|c|c|c|c|c|}
\hline 0 & 0 & 0 & 0 & 0 & Kemampuan dalsm memecahikan masalah & \\
\hline 0 & 0 & 0 & 0 & 0 & Negoalasl & \\
\hline 0 & 0 & 0 & 0 & 0 & Kemampuan analisis & \\
\hline 0 & O & O & O & 0 & Toleransi & \\
\hline 0 & 0 & 0 & 0 & 0 & Kemampuan adaptasil & \\
\hline O & O & 0 & O & O & Layalitas & \\
\hline 0 & 0 & 0 & 0 & 0 & Integritas & \\
\hline O & 0 & 0 & 0 & 0 & Bekerja dengan orang yang berbeda budaya maupun latar belakang & \\
\hline 0 & 0 & 0 & 0 & 0 & Kepemimpinan & \\
\hline 0 & 0 & 0 & 0 & 0 & Kemampuan dalsm memegang tanggungjawab & \\
\hline 0 & 0 & 0 & 0 & 0 & Inisiatif & \\
\hline 0 & O & 0 & 0 & 0 & Manajemen proyek/program & \\
\hline 0 & 0 & 0 & 0 & 0 & Kemampuan untuk memresentasikan ide/produk/laparan & \\
\hline 0 & 0 & 0 & 0 & 0 & Kemampuan dalsm menulis laparan, memo dan dokumen & \\
\hline 0 & 0 & 0 & 0 & 0 & Kemampuan untuk terus helajar sepanjang hayat & \\
\hline Before & & & & & & Nent \\
\hline
\end{tabular}

Gambar 8. Kuisioner Tracer Study DIKTI f17 menggunakan software QTAFI

9. Pada bagian ketujuh disajikan Kompetensi alumni yang dibutuhkan sesuai pekerjaanya dengan item yang sama dengan bagian keenam antara lain mulai dari pengetahuan baik disiplin ilmunya maupun diluar disiplin ilmunya, pengetahuan umum, bahasa inggris, keterampilan internet, keterampilan komputer, berpikir kritis, keterampilan riset, kemampuan belajar, kemampuan berkomunikasi, bekerja di bawah tekanan, manajemen waktu, bekerja secara mandiri, bekerja dengan bekerjasama, kemampuan memecahkan masalah, negosiasi, kemampuan analisis, tolerasi, kemampuan adaptasi, loyalitas, integritas, bekerja dengan latar belakang berbeda, kepemimpinan, tanggung jawab, inisiatif, manajemen program, kemampuan presentasi, kemampuan menulis laporan, serta kemampuan belajar sepanjang hayat dengan rentang penilaian sangat rendah sampai sangat tinggi, apabila selesai, silakan tekan tombol "Next".

\begin{tabular}{|c|c|c|c|c|c|}
\hline \multirow{3}{*}{$\begin{array}{l}\text { f17b } \\
\text { Sangat } \\
\text { Rendah } \\
1\end{array}$} & \multicolumn{5}{|c|}{$\begin{array}{l}\text { Pada saat ini, pada tingkat mana kompetensi di bawah ini diperlukan dalam } \\
\text { pekerjaan? }\end{array}$} \\
\hline & & & & $\begin{array}{l}\text { Sangat } \\
\text { Tinggi }\end{array}$ & \\
\hline & 2 & 3 & 4 & 5 & \\
\hline 0 & 0 & 0 & 0 & 0 & Pengetahuan di bidang atau disiplin ilmu anda \\
\hline 0 & O & ○ & O & ○ & Pengetahuan di luar bidang atau disiplin lilmu anda \\
\hline 0 & 0 & 0 & 0 & 0 & Pengetahuson umum \\
\hline O & ○ & ○ & O & o & Bahasa Inggris \\
\hline 0 & 0 & 0 & 0 & 0 & Ketrampilan internet \\
\hline O & O & 0 & 0 & 0 & Ketrampilan komputer \\
\hline $\mathrm{O}$ & O & O & 0 & 0 & Eerpikir kritis \\
\hline 0 & 0 & O & 0 & 0 & Ketrampilan riset \\
\hline 0 & 0 & 0 & 0 & 0 & Kemampuan belajar \\
\hline 0 & 0 & 0 & 0 & 0 & Kemampuan berkomunikasil \\
\hline 0 & 0 & 0 & 0 & 0 & Bekerja di bawah tekanan \\
\hline 0 & 0 & O & 0 & 0 & Manajemen waktu \\
\hline 0 & O & 0 & 0 & 0 & Eekerja sccara mandiri \\
\hline O & 0 & 0 & O & 0 & Bekerja dalam tim/thekerjasama dengan arang lain \\
\hline
\end{tabular}




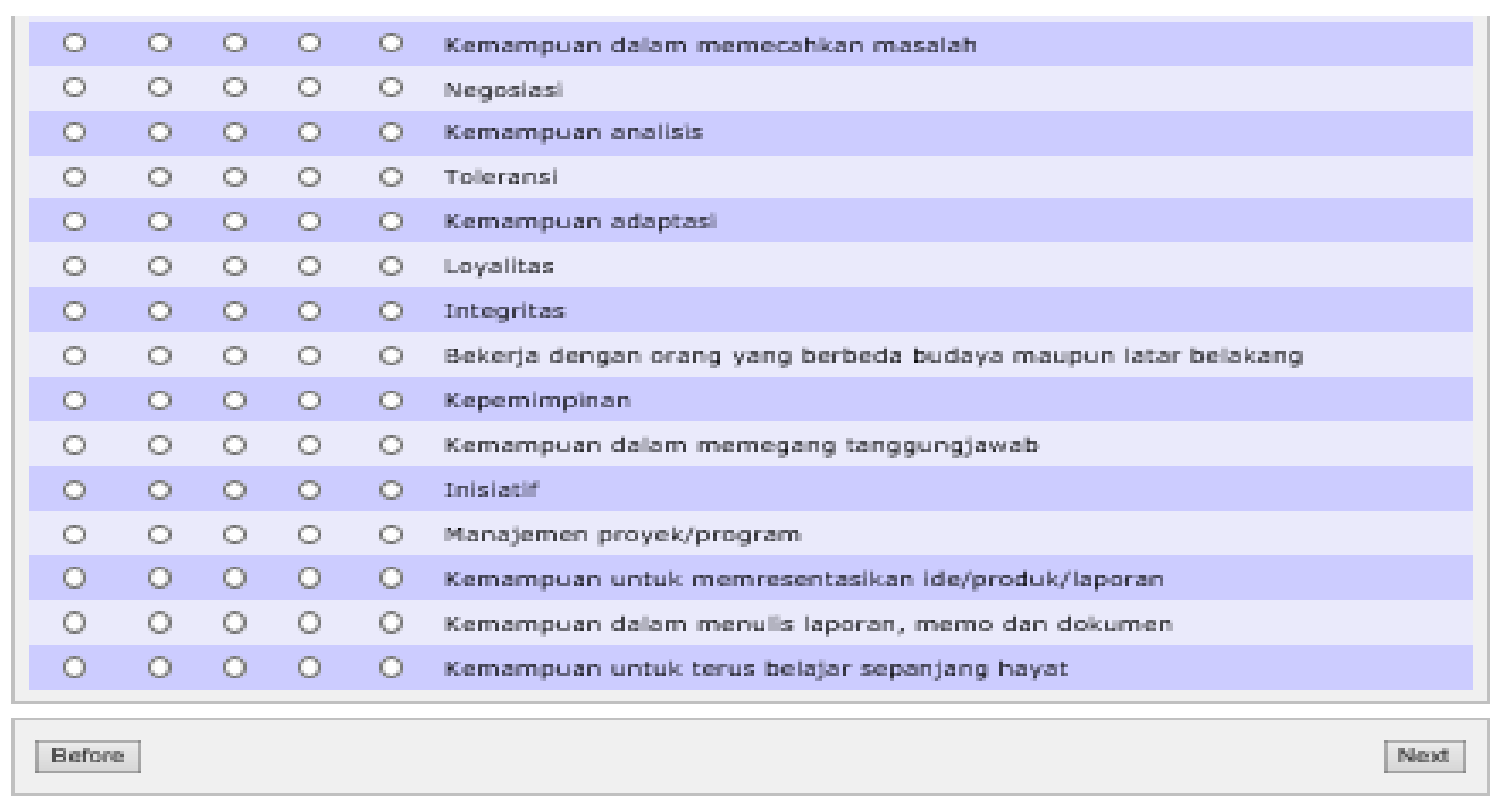

Gambar 9. Kuisioner Tracer Study DIKTI f17b menggunakan software QTAFI

10.Kemudian akan muncul ucapan terima kasih, maka anda sudah ikut berpartisipasi dalam tracer studi STKIP Andi Matappa. Jendela browser sudah dapat di tutup. Terima Kasih Ikut menyukseskan Tracer study STKIP Andi Matappa

\section{Pembahasan}

Alumni STKIP Andi Matappa umumnya tidak berdomisili di daerah Pangkep dan sekitarnya. Setelah lulus, alumni bekerja di tempat yang berbeda-beda. Melaksanakan tracer study membutuhkan partisipasi alumni dalam mengisi kuisoner tracer study. Kesulitan yang dihadapi dalam pelaksanaan tracer study adalah sulitnya menjangkau alumni yang sudah bekerja dan tidak berdomisili di sekitar kampus. Menjangkau alumni tersebut dapat dilakukan dengan menggunakan teknologi yang ada yaitu internet. Penggunaan teknologi internet pada pelaksanaan tracer study di STKIP Andi Matappa akan semakin memudahkan pihak STKIP Andi Matappa dalam mengevaluasi sistem pembelajaran tiap tahunnya. Adanya kuisioner tracer study online membuat lulusan tidak perlu mengisi kuisioner berupa hardcopy (kertas), ataupun melakukan wawancara langsung dengan peneliti secara tatap muka maupun melalui telepon. Menggunakan teknologi yang ada, lulusan hanya membutuhkan koneksi internet dan perangkat komputer atau komputer portable yang bisa diakses kapanpun dan dimanapun. Lulusan dapat menyelesaikan pengisian kuisioner dengan waktu yang singkat dan peneliti dapat dengan mudah mengolah hasil data yang telah diisi oleh responden. Hal ini sesuai dengan Penelitian (Mayang, 2013), yang menyatakan bahwa software tracer study online QTAFI (Questions, Tables and Figures) online yang dikembangkan untuk memudahkan pelaksanaan survei. Software QTAFI online memudahkan responden dalam melakukan pengisian kuisioner dengan kelengkapan fitur untuk menyimpan jawaban secara otomatis apabila responden tidak ingin menyelesaikan pengisian kuisioner dalam satu waktu (Patria, 2012). 
Pelaksanaan pengabdian mendapat tanggapan yang positif dari alumni. Peningkatan pengetahuan dan keterampilan serta literasi terhadap penggunaan teknologi berupa penggunaan komputer dan internet dalam memudahkan kehidupan sehari-hari mereka peroleh melalui pendampingan dan pelaksanaan dari tracer study ini (Sulistiyorini, 2020). Pengabdian ini juga meningkatkan kesadaran alumni untuk turut mendukung program STKIP Andi Matappa dalam melakukan pendataan alumni melalui tracer study berbasis QTAFI. Selain itu, diharapkan pemerintah terbantukan dalam mendapatkan data alumni Perguruan Tinggi yang akurat dan mutakhir untuk digunakan pengambilan kebijakan dan perencanaan pembangunan yang lebih baik. Sosialisasi dan pendampingan yang lebih menyeluruh dapat dijadikan saran agar pelaksanaan Tracer study pada periode berikutnya menjadi lebih efektif.

\section{KESIMPULAN}

Hasil kegiatan pengabdian berupa pendampingan menunjukkan meningkatnya pengetahuan dan pemahaman alumni STKIP Andi Matappa mengenai pengisian kuisioner online QTAFI untuk tracer study. Adapun saran yaitu sebaiknya kegiatan pendampingan pengisian kuisioner tracer study dengan QTAFI rutin dilaksanakan setiap tahun supaya membantu meningkatkan literasi alumni terhadap penggunaan teknologi sekaligus meningkatkan kesadaran alumni untuk mendukung program pemerintah dalam melakukan pendataan alumni melalui tracer study.

\section{UCAPAN TERIMA KASIH}

Ucapan terima kasih diberikan kepada Ketua STKIP Andi Matappa yang memberikan bantuan dana kepada tim pengabdi dalam memperlancar kegiatan pengabdian ini melalui skema pengabdian dana internal kampus. Segala Puji syukur hanya bagi Allah SWT.

\section{DAFTAR PUSTAKA}

Anitah, S. W. (2007). Strategi Pembelajaran di SD. Universitas Terbuka.

Depdiknas. (2005). Kamus Besar Bahasa Indonesia. Depdikas.

Fahmi, R. (2017). Tracer study pada Perguruab Tinggi Ke-Islaman. Maqdis: Jurnal Kajian Ekonomi Islam, 2(1), 67-77.

Fajaryati, N., Pambudi, S., Priyanto, P., Sukardiyono, T., Utami, A. D. W., \& Destiana, B. (2015). Studi Penelusuran (Tracer Study) Terhadap Alumni Program Studi Pendidikan Teknik Informatika Jurusan Pendidikan Teknik Elektronika Fakultas Teknik Universitas Negeri Yogyakarta. Elinvo (Electronics, Informatics, and Vocational Education), 1(1), 44-45. https://doi.org/10.21831/elinvo.v1i1.10878

ILO. (2011). (International Labour Organization) Tracer study-Book 1 Methodology manual. IPEC.

Kemendikbud. (2012). Buku Panduan Sistem Pusat Karir. Kemendikbud.

Mayang. (2013). Evaluasi Tracer Study Untuk Pembelajaran dengan Pendekatan Ergonomi Makro. JTI, 1(4), 284-288.

Muchsin, S, B., \& Hasbahuddin. (2018). Studi Pelacakan Alumni Keguruan STKIP Andi Matappa. JURKAM, 2(1), 26-32.

Ngafifi, M. (2014). Kemajuan Teknologi dan Pola Hidup Manusia dalam Perspektif Sosial Budaya. Jurnal Pembangungan Pendidikan: Fondasi Dan Aplikasi, 2(1), 33-47.

Patria, B. (2012). Survei Online dengan Online Qtafi. Universitas Gajah Mada. 
Ratnaningsih, D, J. (2010). Pemrograman Kuisioner Online dengan Qtafi (Workshop Tracer Study 4-6 Agustus Universitas Indonesia).

Schomburg, H. (2003). Handbook for Graduate Tracer Studies. Center for Research on Higher Education and Work. University of Kassel.

Sulistiyorini. (2020). Pendampingan Pengisian Sensus Online bagi Masyarakat. Jurnal ADIMAS: Jurnal Pengabdian Pada Masyarakat, 4(1), 56-65.

Suryani, K., \& Khairuin. (2015). Tracer Study Online Universitas Bung Hatta Jurnal Edik Informatika. Jurnal Edik Informatika, V2.i1, 16-24.

Syafiq, \& Fikawati. (2008). Final Report Tracer Study University of Indonesia 2008. CDC Universitas Indonesia.

Syarifuddin. (2014). Literasi Teknologi Informasi dan Komunikasi. Jurnal Penelitian Komunikasi, 17(2), 153164.

Wahyuddin. (2016). Peningkatan Mutu dan Relevansi Perguruan Tinggi melalui Tracer Study. Jurnal Competitiveness, 10(2), 91-100.

Wahyudi, H. S., \& Sukmasari, M. P. (2014). Teknologi dan Kehidupan Masyarakat. Jurnal Analisa Sosiologi, $3(1), 13-24$. 